\title{
INFLUENCE OF MCKENZIE PROTOCOL ON POSTMENOPAUSAL LOW BACK
} PAIN

\author{
Asmaa Mahmoud El-Bandrawy ${ }^{1^{*}}$, Hassan Omer Ghareeb ${ }^{2}$ \\ ${ }^{1}$ Faculty of Physical Therapy, Department of Physical Therapy for Obstetrics and Gynecology, Cairo \\ University, Giza, Egypt. \\ ${ }^{2}$ Faculty of Medicine, Department of Obstetrics and Gynecology, Cairo University,Giza, Egypt.
}

\begin{abstract}
Back and spine impairments are more common in women than men and are most common between the ages of 45 and 64. The purpose of this study is to determine the efficacy of McKenzie method on low back pain in postmenopausal women
\end{abstract}

This study was carried out at the Outpatient clinic of faculty of Physical Therapy, Cairo University, between March 2014 and October 2015 upon forty postmenopausal women diagnosed as low back pain. Their age ranged from $(50-65)$ years and $\mathrm{BMl}<30 \mathrm{~kg} / \mathrm{m}^{2}$. Patients were excluded if they have red flags indicative of serious spinal pathology with signs and symptoms of nerve root compromise (with at least two of dermatomal sensory loss, myotomal muscle weakness and reduced lower limb reflexes), individuals with any obvious spinal deformity or neurological disease, previous spinal surgery; patients with pacemaker (or indwelling stimulator); breaks in the skin or lack of normal skin sensation under the area where the electrodes were to be placed or epilepsy.These exclusion criteria were verified by history and physical examination. The patients were informed about the study, and written consent was obtained from all patients.

Patients were randomly assigned into two equal groups (A\& B). Group (A) consisted of twenty patients who received McKenzie therapy in addition to Interferential current.

Group (B) consisted of twenty patients, who received Interferential current only. Treatment program was performed 2 sessions per week over 5 weeks for both groups A\&B. Assessment of all subjects in both groups $(A \& B)$ was carried out before and after the treatment program throughout visual analogue scale and lumber ROM measurements. Showed a highly statistically significant decrease $(P<.0001)$ in group $A$ than in group $B$. The study demonstrates the superiority of the efficacy of the McKenzie method in addition to interferential current, compared with interferential only on low back pain in postmenopausal women.

Key words: Low Back Pain, Menopause, Mckenzie method, Interferential.

\section{INTRODUCTION}

Although menopause is a normal developmental milestone through which all women pass, the transition has been long associated with chronic pain conditions that may be more accurately viewed as secondary to aging [1]. Musculoskeletal disorders are the fourth most common cause of disability following neuropsychiatric disorders, neoplasms, and cardiovascular disease [2].

Women suffer disproportionately from clinical pain conditions such as fibromyalgia and rheumatoid arthritis. Although sex-related factors, including gonadal hormones, influence pain and analgesic response, these represent only one set

*Corresponding author:

Email: asma elbandrawy@yahoo.com

http://dx.doi.org/10.20530/IJTA $33 \quad 20-27$

ISSN 2320-138X (c) 2016 of variables that affect the occurrence of pain in women; others include level of physical activity, body mass index (BMI), vertebral fractures, diabetes, arthritis, and psychosocial status $[3,4]$.

Muscle and joint pain are common complaints throughout life. Low back pain in particular is associated with a large proportion of annual health care expenditures for both men and women. Back and spine impairments are more common in women than men population and are most common between the ages of 45 and 64 [4].

Lifetime prevalence of back pain exceeds $70 \%$. Age, smoking, parity, and occupation are also associated with back pain in women. Female sex hormones, such as high levels of estrogen, may promote joint laxity, thereby increasing the risk of back pain $[5,6]$.

Back exercise, general exercise, stretching, and heat and cold therapy have been effective for relief of back pain. Weight reduction is essential in the obese woman with back pain. However, the 
more disabling the pain, the more difficult it is for women to move. Individuals may then be caught in a vicious cycle: without movement, the ability to burn calories sufficient for weight loss is impeded, and both weight and pain will increase [7].

There is a great variety of interventions for the treatment of patients with chronic low back pain, including the McKenzie method developed by Robin McKenzie in New Zealand in 1981 [8]. The McKenzie Protocol (MP) is one of the most commonly used physical therapy interventions in long-term mechanical LBP with documented effectiveness [9].

The McKenzie method utilizes a system of patient self generated force to mobilize or manipulate the spine through a series of active repeated movements or static positioning and it is based on the patient's pain response to certain movements and postures during assessment [9].

Derangement syndrome is the most prevalent McKenzie treatment classification, refers to pain which is caused by a disturbance in the normal resting position of the affected joint surfaces. McKenzie method can be used for spinal stenosis, hip disorders, sacroiliac disorders, low back pain in pregnancy, zygapophyseal disorders, spondylolysis , spondylolisthesis and post-surgical problems [10].

Electrotherapy, which is a noninvasive, nonpharmacological method involving transcutaneous electrical stimulation, is an additional alternative for low back pain management. The electrotherapy methods also used in some studies on IFC application have been performed, to investigate its effects on induced pain and in relation to different diseases [11].

Interferential therapy utilizes two of these medium frequency currents, passed through the tissues simultaneously, where they are set up so that their paths cross \& they literally interfere with each other - hence another term that has been used in the past but appears to be out of favour at the moment - Interference Current Therapy [12].

The most common use of IFC is to relieve pain, although some therapists also report using IFC for the reduction of swelling, the healing of wounds and fractures, and the restoration of function associated with muscle weakness [13].

Some authors claim that the amplitudemodulated interference wave is what makes IFC potentially effective and that by delivering it at frequencies between 1 and $250 \mathrm{~Hz}$, IFC will elicit a physiological response that leads to pain relief. Whether there is pain relief is not certain because of a lack of experimental research. In addition, the potential mechanism by which pain relief occurs is obscure [14].

The skin offers high impedance at pulse frequencies used with TENS, so it is likely that currents will remain superficial [15].The purpose of IFC therapy is to deliver currents to deep-seated tissue. Currents with a kilohertz cycle duration are used in an effort to overcome skin impedance and penetrate deep into the body [16].

\section{METHODS}

Design

A single-blind controlled trial involving 40 postmenopausal patients diagnosed as low back pain. They were selected from Outpatient Clinics of Physical Therapy, Cairo University. Their age ranged from (50-65) years and $\mathrm{BMI}<30 \mathrm{~kg} / \mathrm{m}^{2}$. Patients were allocated randomly to either group A or B using permuted randomization. Group (A) consisted of twenty subjects, with an average age (58.36 \pm 5.28$)$, and BMI $\left(29.22 \pm 1.33 \mathrm{~kg} / \mathrm{m}^{2}\right)$ who received McKenzie therapy in addition to Interferential current. Group (B) consisted of twenty subjects, with an average age $(59.75$ $\pm 4.79 \mathrm{Yrs})$, and BMI $\left(28.78 \pm 1.84 \mathrm{~kg} / \mathrm{m}^{2}\right)$ who received Interferential current only. Exclusion criteria included red flags indicative of serious spinal pathology with signs and symptoms of nerve root compromise (with at least two of dermatomal sensory loss, myotomal muscle weakness and reduced lower limb reflexes), individuals with any obvious spinal deformity or neurological disease, previous spinal surgery; patients with pacemaker (or indwelling stimulator); breaks in the skin or lack of normal skin sensation under the area where the electrodes were to be placed or epilepsy. Informed consent form was signed by each patient before starting the treatment.

\section{McKenzie therapy for group (A):}

Prior to treatment, the participants were instructed in details on the study procedures. This was followed by a low intensity warm-up phase of five minutes duration comprising active stretching of the upper extremities and low back. Treatment also ended with a cool-down phase comprising of the same low intensity exercise as the warm-up for about five minutes.

McKenzie's exercises for back pain are a series of five progressive positions. The five stages of McKenzie's exercises are prone lying, prone lying while resting on elbows, prone push-ups, progressive extension using pillows and standing extension. 


\section{McKenzie Exercises Step One and Two}

To perform the passive stages of the McKenzie exercise, the patient was asked to lie face down on an exercise mat and her arms was placed parallel with the thorax, with the hands next to the pelvis if this position was uncomfortable, a small pillow was placed beneath her abdomen to lessen the stress on her lower back. Each patient was asked to remain in this position for five minutes. From this position the patient moved to stage two; rise up onto her elbows and placed her forearms flat on the floor. Lift her chin slightly and held this position for a further five minutes.

\section{McKenzie Exercises Step Three and Four}

Stage three was 10 prone push-ups. The patient was asked to place her hands beneath her shoulders and, keeping her hips on the floor, raise her chest off the ground by pressing with her arms. On completion, a pillow was placed beneath her chest and she was relaxed in this extended position. After a few moments, another pillow was added to further increase spinal extension. If she was still comfortable a third and final pillow was added and then this extended position was held for up to 10 minutes.

\section{McKenzie Exercise Step Five}

The fifth and final stage of McKenzie's exercises for lower back pain was standing spinal extensions. The patient was asked to stand with her feet hip-width apart and her hands on her lumbar region, in the area of the posterior superior iliac spine. The researcher hands fixated the pelvis while the patient leaned backwards. From this position, she was asked to lift her chest and lean back. This position was held for 20 to 30 seconds before relaxing. After this movement the patient returned to her starting position and repeated this exercise 10 times.

Participants in group $(A)$ received 10 sessions of 30 minutes each (2 sessions per week over 5 weeks).

\section{Interferential current for both groups (A\&B):}

Each patient was advised to relax in prone lying position then the treated area was cleaned by cotton and alcohol. IFT unit was used to deliver standardized IFT stimulation parameters (frequency $3.85 \mathrm{kHz}, 140 \mathrm{~Hz}$ constant; pulse duration $130 \mu \mathrm{s})$. Two carbon silicone self-adhesive electrodes $(45 \times 102 \mathrm{~mm}$ ) were placed over the T12 and S1 lines. The stimulation was administered for 30 minutes, using a strong, but comfortable intensity that was adjusted according to the tolerance of each patient. Participants in each group received 2 sessions per week for 5 weeks

Assessment of all subjects in both groups (A\& B) was carried out before and after the treatment program throughout a $10-\mathrm{cm}$ VAS, with 0 representing no pain, and 10 representing severe pain and lumber ROM measurements.

\section{Assessment of lumbar flexion and extension:}

Modified Schober method was used to measure anterior flexion and posterior extension. The subject was asked to stand erect with her feet about shoulder-width apart. This position stabilized the pelvis, to aid the patient in maintaining her balance, and helped to increase the consistency of measurements. Then, the therapist stood behind the standing patient and determined the posterior superior iliac spines with both thumbs, and then an ink mark was drawn along the midline of the lumbar spines horizontal to the posterior superior iliac spines to mark the midpoint between the posterior superior iliac spines (PSIS).Another ink mark was made $15 \mathrm{~cm}$ above the original mark.

The tape was pressed firmly against the patient skin, the distance between superior and inferior skin marks was measured. Then the patient was instructed to bend forward into full lumber flexion and the new distance between superior and inferior skin marks was measured. The change in the differences between marks was used to indicate the amount of lumber flexion. This test was performed for three consecutive times and the mean value was considered as the lumber flexion range of motion. To assess lumber extension, the investigator followed the same procedures but the patient was asked to bend backward into full extension as much as she can and the new distance between superior and inferior skin marks was measured. This test was performed for three consecutive times and the

Table 1. Physical characteristics of the patients before the treatment

\begin{tabular}{lcccc}
\hline Groups & Group A & Group B & \multicolumn{2}{c}{ Comparison } \\
\cline { 3 - 5 } & Mean \pm SD & Mean \pm SD & t-value & P-value \\
\hline Age $(\mathbf{y r s})$ & $58.36 \pm 5.28$ & $59.75 \pm 4.79$ & 0.48 & 0.6 \\
BMI(kg/m2) & $29.22 \pm 1.33$ & $28.78 \pm 1.84$ & 0.75 & 0.55 \\
\hline
\end{tabular}


mean value was considered as the lumber extension range of motion.

\section{Assessment of lumbar lateral flexion}

The subject was asked to stand erect with her feet about shoulder-width apart. Lateral flexion was measured as the distance from the tip of the index finger to the floor at maximal comfortable lateral flexion. The patient was instructed to move as far as possible into lateral flexion and try to touch the ground with the head looked behind shoulder.

\section{RESULTS}

Physical Characteristics of the Patients Table 1

\section{Statistical Analysis}

The Data were analyzed using SPSS version 17. and presented using descriptive statistics including the mean, percent and the standard deviation in addition to dependent samples t-test was used for the comparison between the variables. A p-value of less than $0.05 \quad(p<0.05)$ was considered as statistically significant.

\section{Regarding to Visual Analogue Scale}

The statistical difference between the results before and after the treatment program for group (A) was $\mathrm{P}<0.001$, indicating a statistically high significant decrease in pain, while $\mathrm{P}<0.05$ in group (B) indicating a statistically significant decrease in pain as shown in Table (2).
Regarding to lumber ROM measurements for group (B)

In group (B) the mean showed statistical significant $(P<0.05)$ increase in lumber flexion, lumber extension, right lateral flexion, left lateral flexion for post-treatment as shown in Table (4).

Comparative analysis of pain intensity between study and control group.

There was no statistical significant difference between both groups (A\&B) before the treatment while post-treatment mean values of VAS for group (A) was lower than mean values of group $B$. This reveals significant reduction of the pain intensity in group $A$ than in group $B$ as shown in Table (5).

Comparative analysis of lumber Flexion between study and control group.

There was no statistical significant difference between both groups A\&B before the treatment, while post-treatment mean values of lumber flexion ROM for group (A) was more than that of group (B). This revealed statistically significant improvement in lumber flexion ROM in group $A$ than in group $B$ as shown in Table 6.

\section{Comparative analysis of lumber extension ROM between both groups A\&B}

There was no statistical significant difference between both groups A\&B before the treatment, while post-treatment mean values of lumber

Table 2. The mean values of visual analogue scale before and after treatment for Both groups A\&B

\begin{tabular}{ccccc}
\hline VAS & Before treatment & After treatment & \multicolumn{2}{c}{ Significance } \\
\cline { 3 - 5 } & & & T- value & P-value \\
\hline Group (A) & $7.88 \pm 1.3$ & $2.9 \pm 0.88$ & 23.88 & 0.001 \\
Group (B) & $7.56 \pm 0.98$ & $3.68 \pm 0.65$ & 20.84 & 0.05 \\
\hline
\end{tabular}

Regarding to lumber ROM measurements for group (A)

In group $(A)$ the mean value of lumber flexion showed a highly statistical significant $(P<0.001)$ increase. Value of lumber extension showed highly statistical significant $(P<0.001)$ increase in the ROM. There was a highly statistical significant difference $(P<0.001)$ in right lateral flexion and left lateral flexion as shown in Table (3). extension ROM for group (A) was more than that of group (B). This revealed statistically significant improvement in lumber extension ROM in group $A$ than in group B as shown in Table 6.

\section{Comparative analysis of right, lateral Lumber Flexion ROM between both groups A\&B}

There was no statistical significant difference between both groups A\&B before the treatment, while there was significant difference after the

Table 3. Mean value of lumber ROM (flexion, extension, right \&left lateral flexion) of patient in group (A)

\begin{tabular}{lcccc}
\hline Variables & Before treatment & After treatment & \multicolumn{2}{c}{ Significance } \\
\cline { 3 - 4 } & & & T-value & P-value \\
\hline Flexion & $6.22 \pm 1.95$ & $8.52 \pm 1.3$ & 15.80 & 0.001 \\
Extension & $3.67 \pm 1.43$ & $5.56 \pm 1.18$ & 10.46 & 0.001 \\
Right lateral flexion & $43 \pm 6.7$ & $37 \pm 8.2$ & 5.34 & 0.001 \\
Left lateral flexion & $44 \pm 6.77$ & $38.4 \pm 6.45$ & 14.56 & 0.001 \\
\hline
\end{tabular}


Table 4. Mean value of lumber ROM (flexion, extension, right \&left lateral flexion) of patient in group (B)

\begin{tabular}{lcccc}
\hline Variables & Before treatment & After treatment & \multicolumn{2}{c}{ Significance } \\
\cline { 3 - 4 } & & & T-value & P-value \\
\hline Flexion & $5.57 \pm 1.8$ & $6.76 \pm 1.43$ & 10.09 & 0.05 \\
Extension & $3.67 \pm 1.43$ & $4.32 \pm 1.98$ & 10.66 & 0.05 \\
Right lateral flexion & $42.96 \pm 6.22$ & $40 \pm 6.3$ & 6.56 & 0.05 \\
Left lateral flexion & $45.53 \pm 6.77$ & $42.52 \pm 6.85$ & 7.48 & 0.05 \\
\hline
\end{tabular}

Table 5. Comparative analysis of pain intensity between both groups A\&B

\begin{tabular}{ccccc}
\hline & VAS & & Mean \pm SD & \multicolumn{2}{c}{ Significance } \\
\cline { 3 - 4 } & & & T- value & P value \\
\hline Before & Group A & $7.88 \pm 1.3$ & -0.17 & 0.86 \\
treatment & Group B & $7.56 \pm 0.98$ & & 0.04 \\
After & Group A & $2.9 \pm 0.88$ & -3.17 & 0.04 \\
treatment & Group B & $3.68 \pm 0.65$ & & \\
\hline
\end{tabular}

Table 6. Comparative analysis of lumber flexion and extension between both groups A\&B

\begin{tabular}{lcccr}
\hline & \multicolumn{3}{c}{ Lumber Flexion } & \\
& Group A & Group B & \multicolumn{2}{c}{ Significance } \\
\cline { 3 - 5 } & & & T- value & P value \\
\hline Before treatment & $6.22 \pm 1.95$ & $5.57 \pm 1.8$ & 0.9 & 0.36 \\
After treatment & $8.52 \pm 1.3$ & $6.76 \pm 1.43$ & -3.45 & 0.001 \\
& & Lumber extension & 0.8 & 0.37 \\
\hline Before treatment & $3.67 \pm 1.43$ & $3.67 \pm 1.43$ & -3.34 & 0.001 \\
After treatment & $5.56 \pm 1.18$ & $4.32 \pm 1.98$ & & \\
\hline
\end{tabular}

Table 7. Comparative analysis of right and left lateral Lumber Flexion ROM between study and control group

\begin{tabular}{lcccr}
\hline & \multicolumn{2}{c}{ Right Lateral Lumber Flexion } & & \\
\hline & Group A & Group B & \multicolumn{2}{c}{ Significance } \\
\cline { 3 - 4 } & & & T- value & P value \\
\hline Before treatment & $43 \pm 6.7$ & $42.96 \pm 6.22$ & 0.47 & 0.63 \\
After treatment & $37 \pm 8.2$ & $40 \pm 6.3$ & -2 & 0.05 \\
& & Left Lateral Lumber extension & & 0.8 \\
\hline Before treatment & $44.3 \pm 6.77$ & $45.53 \pm 6.77$ & -0.23 & 0.05 \\
After treatment & $38.4 \pm 6.45$ & $42.52 \pm 6.85$ & -2.02 & \\
\hline
\end{tabular}

treatment in favor of group (A). This revealed statistically significant improvement in right, lateral lumber flexion ROM in group $A$ than in group B as shown in Table 7.

Comparative analysis of Left, lateral Lumber
Flexion between study and control group.

There was no statistical significant difference between both groups A\&B before the treatment, while there was significant difference after the treatment in favor of group (A). This revealed statistically significant improvement in Left, lateral lumber flexion ROM in group A than in group B as shown in Table 7.

\section{DISCUSSION}

Although back pain occurs in both younger and older women, some women experience an increase in back pain during the menopausal transition, and women often attribute the complaints to menopause [17].

Development of a clinical management model for back pain patients from previously published 
guidelines and systematic reviews. McKenzie approach was listed as a recommended therapeutic intervention for acute and for chronic back pain with 'poor' scientific evidence; and for sub-acute back pain with 'moderate' scientific evidence [18].

The results of the present study revealed that, there was significant decrease in the pain in group A who was treated by Mckenzie exercises in addition to interferential current and this come in agreement with Petersen et al., [19] who stated that pain reduction in the Mckenzie group might have occurred due to other causes without changes in the thickness of abdominal and multifidus muscles. This approach was focused on sustained postures or repeated movements, and pain reduction might have been due to postural correction.

Active exercise can be described as functional exercise performed by the patient or client. Previous studies have shown that active exercise, irrespective of the type is more effective in the management of patients with long-term LBP than passive therapy $[20,21]$.

Health-Related Quality of Life (HRQoL) in patients with long-term mechanical low-back pain (LMLBP) decreases with pain severity. Each of Mckenzie protocol (MP), static and dynamic back extensors endurance exercises significantly improved HRQoL in long-term mechanical lowback pain (LMLBP). However, the addition of dynamic back extensors endurance exercise to MP led to greater improvement in HRQoL [22].

There was limited evidence to support use of Mckenzie method as a treatment for both acute and chronic back pain, and moderate evidence indicating its value as a diagnostic tool and prognostic indicator. Stabilization exercises were more effective than Mckenzie exercises in reducing pain and disability $[23,24]$.

Using 20 minutes of IFC on acute low back pain patients provide reductions in their pain observed using a handheld dynamometer [25].

Johnson and Ashton, [26] showed that TENS and IFC had significant effects in relation to pain intensity reduction, disability improvement and reduction of medication consumption, immediately after each electrotherapy session and after ten sessions, in comparison with the controls

Cramp et al.,[27] Did not find significant differences in pain intensity among healthy people subjected to both types of electric current(TENS \& IFC). Similar results were found by Cheing and Hui-
Chan [28] showing a slight advantage with IFC over TENS in some ways.

Interferential current and TENS therapy are effective for pain relief in patients with low back pain. The study showed equal analgesic efficacy of both treatments [29].

There was no difference between TENS and interferential current for chronic low back pain treatment [30].

One high quality trial found a significant reduction in pain and disability after interferential therapy and after motorized lumbar traction plus massage [31].

There were no differences in the magnitude of analgesia between IFC and TENS. Interferential currents reduced pain intensity to a greater extent than sham electrotherapy [11].

IFC elevates pain threshold when compared with no treatment and with sham electrotherapy using cold-induced pain in otherwise pain-free subjects [32].

Interferential currents reduced the intensity of experimentally induced ischemic pain, IFC produced significantly greater analgesia than sham and no-treatment control groups under the present experimental conditions [33].

Zambito et al., [34] provided the first evidence that interferential currents IFT and $\mathrm{H}$ horizontal therapy $T$ therapy are significantly effective in alleviating both pain and disability in patients with chronic low back pain due to multiple vertebral fractures.

Recent surveys have consistently reported that IFT is the most commonly used electrotherapeutic modality in Britain and Ireland for the physiotherapeutic management of patients with LBP, that IFT was preferred by $44.1 \%$ of 813 physiotherapists they surveyed; furthermore, only $23.4 \%$ of respondents failed to report any use of IFT in the treatment of LBP conditions. This modality has widespread ownership, popularity, and usage among therapists in Australia and Canada [35].

\section{CONCLUSION}

The study demonstrates the superiority of the efficacy of the McKenzie method in addition to interferential current, compared with interferential only on low back pain in postmenopausal women.

What is already known on this topic: 
- The McKenzie Protocol (MP) is one of the most commonly used physical therapy interventions in long-term mechanical LBP.

- Interferential current is an additional alternative for low back pain management

What this study adds

- The superiority of the efficacy of the McKenzie method in addition to interferential current, compared with interferential only on low back pain in postmenopausal women.

\section{ACKNOWLEDGEMENTS}

Many thanks, to all patients who participated in this study for their co-operation.

\section{COMPETING INTERESTS}

Authors have declared that no competing interests exist.

\section{AUTHOR'S CONTRIBUTIONS}

All authors have read and agreed to the final version of this manuscript and have equally contributed to its content.

\section{REFERENCES}

1. ROUSSEAU M, GOTTLIEB S. Pain at midlife. Journal of Midwifery \& Women's Health. 2004 Nov;49(6):529-38. Available from: http://dx.doi.org/10.1016/s1526-9523(04)00442-8.

2. Schopper D. Estimating the burden of disease in one Swiss canton: what do disability adjusted life years (DALY) tell us? International Journal of Epidemiology. 2000 Oct 1;29(5):871-7. Available from: http://dx.doi.org/10.1093/ije/29.5.871.

3. Fillingim RB, Ness TJ. Sex-related hormonal influences on pain and analgesic responses. Neuroscience \& Biobehavioral Reviews. 2000 Jun;24(4):485-501. Available from: http://dx.doi.org/10.1016/s0149-7634(00)00017-8.

4. Andersson GB. Epidemiological features of chronic low-back pain. The Lancet. 1999 Aug;354(9178):581-5. Available from: http://dx.doi.org/10.1016/s0140-6736(99)01312-4

5. Musgrave DS, Vogt MT, Nevitt MC, Cauley JA. Back Problems Among Postmenopausal Women Taking Estrogen Replacement Therapy. Spine. 2001 Jul;26(14):1606-12. Available from: http://dx.doi.org/10.1097/00007632-20010715000023.

6. Finset A, Øverlie I, Holte A. Musculo-skeletal pain, psychological distress, and hormones during the menopausal transition. Psychoneuroendocrinology. 2004 Jan;29(1):49-64. Available from: http://dx.doi.org/10.1016/s0306-4530(02)00134-8.
7. Han TS, Schouten JSAG, Lean MEJ, Seidell JC. The prevalence of low back pain and associations with body fatness, fat distribution and height. International Journal of Obesity. 1997 Dec 18;21(7):600-7. Available from: http://dx.doi.org/10.1038/sj.ijo.0800448.

8. McKenzie R, May S. Mechanical diagnosis \& therapy. 2nd edition. Vol. 1. Waikanae, New Zealand: Spinal Publications New Zealand Ltd.; 2003. The lumbar spine.

9. Machado LAC, de Souza M von S, Ferreira PH, Ferreira ML. The McKenzie Method for Low Back Pain. Spine. 2006 Apr;31(9):E254-E262. Available from:

http://dx.doi.org/10.1097/01.brs.0000214884.1850 2.93.

10. May S, Donelson R. Evidence-informed management of chronic low back pain with the McKenzie method. The Spine Journal. 2008 Jan;8(1):134-41. Available from: http://dx.doi.org/10.1016/j.spinee.2007.10.0171.

11. Johnson MI, Tabasam G. An investigation into the analgesic effects of interferential currents and transcutaneous electrical nerve stimulation on experimentally induced ischemic pain in otherwise pain-free volunteers. Phys Ther. 2003; 83 (3): 20823.

12. Raimundo AKS, Brandão DL, Lucena KG. Comparative study of the analgesic effect between frequencies of interferential current in the fibromyalgia. Fisioter Mov. 2004; 17 (4):65-72.

13. Johnson MI, Tabasam G. A questionnaire survey on the clinical use of interferential currents (IFC) by physiotherapists. In: The Pain Society of Great Britain Annual Conference Abstracts. Leicester, United Kingdom: Pain Society of Great Britain; 1998.

14. Low J, Reed A. Electrical stimulation of nerve and muscle. In: Low J, Reed A, eds. Electrotherapy Explained: Principles and Practice, 2nd edn. Oxford, United Kingdom: Butterworth-Heinemann Ltd;1994 .P.39-116

15. Woolf C, Thompson J. Segmental afferent fibreinduced analgesia: transcutaneous electrical nerve stimulation (TENS) and vibration. In: Wall $P$, Melzack R. Textbook of Pain, eds. Edinburgh, Scotland: Churchill Livingstone;1994 .P.1191-1208

16. Martin D. Interferential for pain control. In: Kitchen S, Bazin S, Clayton's Electrotherapy, 10th ed. London, United Kingdom: WB Saunders Co Ltd;1994 P.306-315

17. Brynhildsen JO, Björs E, Skarsgård C, Hammar ML. Is Hormone Replacement Therapy a Risk Factor for Low Back Pain Among Postmenopausal Women? Spine. 1998 Apr;23(7):809-13. Available from: http://dx.doi.org/10.1097/00007632-19980401000014. 
18. Poitras $S$, Rossignol $M$, Dionne $C$, Tousignant $M$, Truchon M, Arsenault B, Allard P, Cote M, Neveu A. An interdisciplinary clinical practice model for the management of low-back pain in primary care: the CLIP project. BMC Musculoskeletal Dis;http://www.biomedcentral.com/1471-

2474/9/54, 2008.

19. Petersen $\mathrm{T}$, Larsen $\mathrm{K}$, Jacobsen $\mathrm{S}$. One-Year Followup Comparison of the Effectiveness of McKenzie Treatment and Strengthening Training for Patients With Chronic Low Back Pain. Spine. 2007 Dec;32(26):2948-56. Available from: http://dx.doi.org/10.1097/brs.0b013e31815cda4a.

20. Kankaanpää $M$, Taimela $S$, Airaksinen $O$, Hänninen O. The Efficacy of Active Rehabilitation in Chronic Low Back Pain. Spine. 1999 May;24(10):1034-42. Available from: http://dx.doi.org/10.1097/00007632-19990515000019.

21. Rainville J, Hartigan C, Martinez E, Limke J, Jouve C, Finno $M$. Exercise as a treatment for chronic low back pain. The Spine Journal. 2004 Jan;4(1):106-15. Available from: http://dx.doi.org/10.1016/s15299430(03)00174-8.

22. Mbada CE, Ayanniyi O, Ogunlade SO, Orimolade EA, Oladiran AB, Ogundele AO. Influence of Mckenzie protocol and two modes of endurance exercises on health-related quality of life of patients with longterm mechanical low-back pain. Pan Afr Med J. 2014; 18 (17): 1-5.

23. Danish Institute for Health Technology Assessment; Low-back pain. Frequency, management and prevention from an HTA persective. 1999; 1-106.

24. Hosseinifar $M$, Akbari $M$, Behtash $H$, Amiri $M$, Sarrafzadeh J. The Effects of Stabilization and Mckenzie Exercises on Transverse Abdominis and Multifidus Muscle Thickness, Pain, and Disability: A Randomized Controlled Trial in NonSpecific Chronic Low Back Pain. Journal of Physical Therapy Science. 2013;25(12):1541-5. Available from: http://dx.doi.org/10.1589/jpts.25.1541.

25. Romani ED, Spironello A, Almeida M, Souza MZ. Efeito da terapia interferencial em pacientes com lombalgia aguda. Anais do IV Simpósio Internacional de Fisioterapia. Rev Fisioter Univ São Paulo. 1999;6:36-71.

26. Johnson $\mathrm{MI}$, Ashton $\mathrm{CH}$, Thompson JW. The consistency of pulse frequencies and pulse patterns of transcutaneous electrical nerve stimulation (TENS) used by chronic pain patients. Pain. 1991 Mar;44(3):231-4. Available from: http://dx.doi.org/10.1016/0304-3959(91)90090-k.

27. Cramp FL, Noble G, Lowe AS, Walsh DM, Willer JC. A controlled study on the effects of transcutaneous electrical nerve stimulation and interferential therapy upon the RIII nociceptive and $\mathrm{H}$-reflexes in humans. Archives of Physical Medicine and Rehabilitation. 2000 Mar;81(3):324-33. Available from: $\quad$ http://dx.doi.org/10.1016/s00039993(00)90079-0.

28. Cheing GLY, Hui-Chan CWY. ANALGESIC EFFECTS OF TRANSCUTANEOUS ELECTRICAL NERVE STIMULATION AND INTERFERENTIAL CURRENTS ON HEAT PAIN IN HEALTHY SUBJECTS. Journal of Rehabilitation Medicine. 2003 Jan 1;35(1):15-9. Available from: http://dx.doi.org/10.1080/16501970306101.

29. Grabiańska E, Leśniewicz J, Pieszyński I, Kostka J. Comparison of the analgesic effect of interferential current (IFC) and TENS in patients with low back pain. Wiad Lek. 2015; 68(1): 13-9.

30. Facci LM, Nowotny JP, Tormem F, Trevisani VF. Effects of transcutaneous electrical nerve stimulation (TENS) and interferential currents (IFC) in patients with nonspecific chronic low back pain: randomized clinical trial. Sao Paulo Med J.2011; 129(4) :206-16.

31. Werners R, Pynsent PB, Bulstrode CJK. Randomized Trial Comparing Interferential Therapy With Motorized Lumbar Traction and Massage in the Management of Low Back Pain in a Primary Care Setting. Spine. 1999 Aug;24(15):1579. Available from: $\quad$ http://dx.doi.org/10.1097/00007632199908010-00012.

32. Johnson MI, Tabasam G. A double blind placebo controlled investigation into the analgesic effects of inferential currents (IFC) and transcutaneous electrical nerve stimulation (TENS) on cold-induced pain in healthy subjects. Physiotherapy Theory and Practice. 1999 Jan;15(4):217-33. Available from: http://dx.doi.org/10.1080/095939899307630.

33. Johnson MI, Tabasam G. A single-blind placebocontrolled investigation into the analgesic effects of interferential currents on experimentally induced ischaemic pain in healthy subjects. Clin Physiol Funct Imaging. 2002 May;22(3):187-96. Available from: $\quad$ http://dx.doi.org/10.1046/j.1475097x.2002.00416.x.

34. Zambito A, Bianchini D, Gatti D, Rossini M, Adami S, Viapiana O. Interferential and horizontal therapies in chronic low back pain due to multiple vertebral fractures: a randomized, double blind, clinical study. Osteoporos Int. 2007 Jul 4;18(11):1541-5. Available from: http://dx.doi.org/10.1007/s00198007-0391-3.

35. Foster NE, Thompson KA, Baxter GD, Allen JM. Management of Nonspecific Low Back Pain by Physiotherapists in Britain and Ireland. Spine. 1999 Jul;24(13):1332. Available from: http://dx.doi.org/10.1097/00007632-19990701000011 